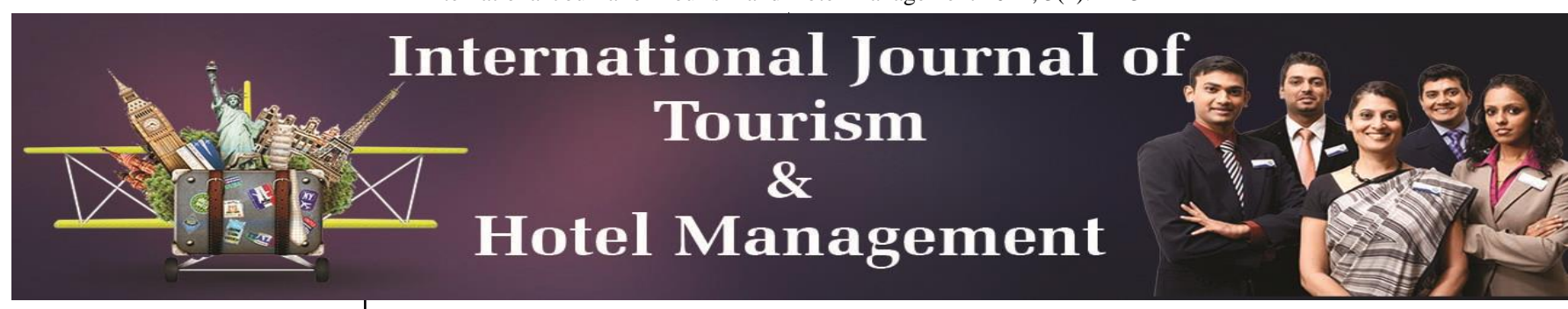

E-ISSN: 2706-9591

P-ISSN: 2706-9583

IJTHM 2021; 3(2): 21-31

Received: 07-05-2021

Accepted: 09-06-2021

Maria Silvia Avi

Professor in Business

Administration Management, Department Ca'Foscari

Venezia, S Giobbe, Cannaregio, Venezia, Italy
Corresponding Author: Maria Silvia Avi

Professor in Business

Administration Management,

Department Ca' Foscari

Venezia, S Giobbe, Cannaregio,

Venezia, Italy

\section{The budget in hotel companies as a business management tool and as a means of empowering managers}

\section{Maria Silvia Avi}

DOI: https://doi.org/10.22271/27069583.2021.v3.i2a.28

\begin{abstract}
The budget in hotel businesses is becoming increasingly important. This applies to large companies and small hotels. This document must be drawn up in the knowledge that the complexity of the business requires a set of documents that together form the annual hotel planning plan. The correct understanding of each document that makes up the hotel's master budget is an essential step towards improving business management by making managers more aware of the efficiency and effectiveness of their actions and, above all, of the impact that these actions have on financial reporting of the Hotel.
\end{abstract}

Keywords: hotel companies, business management, empowering managers

\section{Introduction}

The master budget in hotel businesses: economic budget, asset budget and financial budget: introductory concepts

Nowadays, the management of a company needs tools - not necessarily accounting tools that allow, on the one hand, to understand the existing situation in the company thoroughly and, on the other, to identify the "route" that helps to maintain and reach the balance between the economic-financial and equity components of the company.

In the hotel sector, the importance of these instruments is amplified. The extremely rigid cost structure, and therefore difficult to change, which characterises these companies, means that improvised management can have extremely negative consequences on the company's profitability and financial dynamics. Managing a hotel based on the perceptions - more or less verified in the field - of the company management can undermine the economic, patrimonial and financial equilibrium of the company; a situation which can easily lead to a sudden and irreversible failure of the company strategy before with consequent crisis.

The identification of clear and consistent objectives, the implementation of actions to pursue these objectives, the search for the causes of any deviations between actual data and planned values are therefore ineliminable "management phases" so that the hotel business can meet the expectations of the members of the economic entity and, in general, of the participants in the production process.

From this point of view, management control, intended as a guiding activity carried out by managers, applying the mechanism to ensure the acquisition and use of resources effectively and efficiently in order to achieve the set economic objectives, is transformed into an operating system whose shortcomings can significantly affect the company's performance.

In order for the control system to play its role as a tool to promote the effective and efficient management of the hotel business, it is necessary to definitively overcome the pseudopunitive vision of control that often permeates the culture of hotel managers.

As long as the management control will be "read" as a tool to limit the autonomy of the subjects through a strict and sequestered inspection of the results achieved, the operating system in our interest will undoubtedly be destined to total failure. A circumstance which, with high probability, can lead not only to a useless superstructure - but not for this reason inexpensive - but also to an anti-structure whose action contrasts irremediably with the company objectives.

Therefore, controlling does not mean inspecting, checking, blaming, searching for errors made in management, but rather, it means guiding the management process. 
The control system, intended as the result of the systemic coordination of the information support to decisions, the map of responsibilities and finally, the process, presupposes, for its proper functioning, the implementation of a severe and consistent business planning.

\section{Function of budget in hotel}

The planning phase, in fact, by identifying - in a clear and precise way - the objectives that the hotel company intends to pursue, if correctly implemented, plays the role of "driving element" of the implementation of a decisionmaking system based on cognitive elements that allow the rationalisation of the choices to be made.

The planning activity implies the implementation of a concatenated series of steps that allow improving the knowledge regarding both the scenario outside the company and the situation inside it. Information that, inevitably, helps to make the company's decision- planning means setting oneself achievable objectives (we will see later what meanings this term can assume), whose identification implicitly presupposes the implementation of:

\section{Analysis of the national and international economic situation}

The trend and evolution of the general economic dynamics of the States influence, the trend of company performance. This is all the more accurate, the more we focus our attention on the hotel sector. In this market, fact, the income dynamics characterising the various countries act as a driving factor or, on the contrary, a braking factor for the tourist flows leaving and or arriving in the countries. An economic crisis involving, for example, the United States would undoubtedly result in a drop in the flow of tourists arriving from that country. An economic crisis can also cause significant reductions in direct flows to the profit and lossly devastated country. The lack of adequate infrastructure, services, goods and comforts to which tourists are accustomed has negative consequences, not only on those departing from that country but also on those who, potentially, finding another situation, could have opted for that country as a privileged destination for their holidays. It should be noted that a possible unfavourable economic trend at a national and international level could negatively influence not only leisure tourism but also business tourism. Companies tend to be less willing to let their employees travel if the economic situation is not favourable, as it is highly probable that this negative trend will also have more or less sensitive implications for the company in question.

Naturally, spa tourism and what we might call "beauty tourism" may also suffer the negative consequences of a global recession. An unfavourable economic trend may $n$ fact reduce the number of people who, even though they do not have any particular need to implement the treatments provided in these centres, in the presence of a favourable income situation, would have been users of the services offered by spa hotels and "beauty farms".

From these considerations, it can be understood how the analysis of national and international economic trends, especially in particular economic sectors, such as the hotel industry, represents an element that can ensure that the planning is implemented in a congruous and rational way and, therefore, is aimed at the implementation of an effective and efficient management of the company.

\section{Analysis of the situation in the specific market to which} the company belongs.

Refining one's knowledge of the market trend in which the company is located is a necessary step for the company's management to be carried out rationally. Setting ambitious objectives, even in the presence of a crisis in the sector, can represent an element of strength for the company if the planning has been carried out in the awareness of the difficulties faced by the market in which the company operates. This leads the company management to implement a series of suitable countermeasures to counter the bad performance of the sector. Setting ambitious objectives without having previously carried out an in-depth study of the situation in the sector can instead be detrimental because the lack of knowledge of the general economic trend of the market may favour the setting of unreachable objectives. This can also have severe consequences if there is an extremely rigid cost structure in companies - as it happens in hotel companies. If I foresee an influx of clients equal to 40,000 presences per year, the hiring of personnel will be adequate to this objective, as well as many operating costs (e.g. room cleaning and/or hotel external contracts, leasing contracts for the management of green plants, contracts for the purchase of food, beverages and liquors, etc.) will be at levels that are adequate with respect to the sales objective defined in the planning. There is no need to dwell on the deleterious consequences that this situation could create if sales were not correctly parameterized, due to lack of information and other reasons, these costs should $\mathrm{n}$ any case be incurred even in the absence of corresponding revenues. This situation does not need to take long to lead to the liquidation $d$ /or bankruptcy of any company. Even the underestimation of sales can cause severe economic and financial consequences within the company. In fact, setting up a structure that is undersized with respect to the actual demand makes it impossible to accommodate unforeseen customer flows or has detrimental consequences in terms of the quality of service offered. In both cases, the underestimation of sales has an extremely negative impact on the company's income and financial balance. It is clear, therefore, that the rigidity characterizing hotel companies is an incentive to carry out serious planning based on the maximum amount of information that can be inferred from internal and external research.

\section{Analysis of the company's main competitors}

It is unthinkable that serious planning can be carried out within the hotel business without, at the same time, a particularly in-depth analysis of the overall situation and the management actions taken by the leading competitors. The hotel's marketing activities must serve not only to induce certain behaviours in consumers but also to counteract the management actions implemented by its competitors.

\section{In-depth analysis of the evolution of the company's economic-financial and equity situation}

It is not possible to set income, financial and equity objectives without knowing the company's past and current situation. Planning, therefore, presupposes the implementation of an analytical study of the company's past and present which, in the absence of the will to implement management control, is rarely carried out thoroughly and systematically. 
Establishment of a set of "operational" objectives with overall internal consistency. The identification of a grid of objective parameters necessarily requires the prior execution of an analysis aimed at verifying the coherence of the explicit objectives, the absence of which would make it impossible to pursue what is "programmed" globally.

It is well known that the management of a company requires the identification of the objectives to be achieved. Often, however, this phase is implemented in an "implicit" way; everything is evident in the mind of the entrepreneur, but nothing is formalized and made explicit to the participants in the business decision-making process. This frequently involves the "extemporaneous" identification of a grid of intrinsically inconsistent objectives; a circumstance that causes serious consequences at both income and financial/equity level.

Programming, on the other hand, means making the objectives to be pursued explicit and formalized. It is evident how, according to this meaning, planning needs an internal coherence whose absence undermines the construction of the grid of objective parameters identified.

These considerations, therefore, make it possible to interpret programming as a sub-system whose presence, especially in companies characterized by high-cost rigidity and a significant dynamism of the market to which it belongs, such as hotels, must be considered not opportune but indispensable so that management can achieve satisfactory economic-financial performance.

In order to avoid dangerous misunderstandings, it is necessary to give a "temporal" meaning to the planning. Until a few years ago, scholars, almost unanimously, distinguished - in a clear-cut manner - planning from programming, and management control from strategic control. In this way, the clear separation that was believed to exist between the short and long term was underlined. In this doctrinal context, efficiency was generally interpreted as a short-term objective, while the attainment of effectiveness was often considered as an element concerning, above all, long-term choices.

In recent years, with regard to these "profound" distinctions, the most evolved doctrine has highlighted how the contrast between elements considered in the past to be relevant to the short term and variables considered concerning the long term, in reality, does not exist or rather, a connection between "short" and "long" decisions can be identified such that these choices are not opposed or clearly distinguishable but overlapping and intersecting. This vision of management control necessarily implies a clear rejection of the idea that programming has exclusively short-term implications. This entails the simultaneous overcoming of the opinion that the budget substantially represents the first year of the business plan.

In order for the programming to play its proper role, it is necessary to reach a phase of formal clarification of the objectives to be pursued. The budget is the formal representation of the objectives to be achieved in the period (generally an exercise which is divided into several subaggregates).

If interpreted from this point of view, the budget, even though it has as its temporal reference the exercise or fractions of it, loses the hypothetical output characteristic expressed in quantitative-monetary terms of the decisionmaking process, which is biunivocally correlated to shortterm choices, and becomes a composite document whose function is to make explicit the system of objectives that must be pursued in the period of time to which the document itself refers. Objectives that, for the reasons explained above, can be of a very short-term tacticaloperational nature or have a long-term strategic value. For this reason, the doctrine, highlighting the clear link between short and long term choices, notes how the budget is integrated and interconnected with the company strategy. This document, therefore, becomes an instrument for the implementation of strategies and strategic control, even though it considers "only" a limited period.

The importance that is unanimously acknowledged to the budget in the field of business management is rooted in the fact that this document, in addition to performing its own planning and guidance functions, develops a series of other functions that are essential for the pursuit of efficiency and effectiveness. These functions can be summarised as follows:

\section{Coordination and integration function}

Since the budget is a composite document consisting of a set of analytical documents, within which the objectives to be pursued are explained, it is necessary that, in a face prior to the drafting of this document, an agreement has been reached between all the managers who participated in the setting of the planned values. The contrasts that inevitably arise at the time of defining the objectives (think, for example, of the fact that the kitchen manager would certainly like to have at his disposal a stock of food stocks that is extremely varied and probably high in quantitative terms, while the head of Food \& Beverage, in the hypothesis, that he has been made responsible also in financial terms, aims at the maximum containment of the value of the stocks because a high amount of inventories has substantial financial repercussions) must, in fact, necessarily be overcome when it comes to agreeing on the quantitative values to be included in the budget.

Implicitly, therefore, the budget represents an instrument with high organizational value because its correct use allows to overcome conflicts, whether latent or explicit.

This "organizational" feature is combined with the coordination function of "target parameters" that the budget is called upon to perform. When the objectives that are to be pursued are quantitatively explained, it is necessary to evaluate the coherence between them in order to avoid the attempt, which would inevitably be destined to fail, to achieve in a "schizophrenic" way a set of conflicting objective parameters within them.

The application of the budgetary equation, therefore, ensures coordination by requiring consistency between proposed programmes and expected profitability. This results in the "discarding" of all options that are not congruent with the returns that ownership and management consider satisfactory.

\section{Negotiation function}

Since the budget performs a significant function of coordination and organizational integration, it is obvious how this document must, necessarily, also play a role as a negotiating tool, without which, the coordination objective could certainly not be achieved.

\section{Function to evaluate alternatives}

Some scholars interpret the budget as a tool to evaluate the 
economic and financial consequences of the company's choices. According to this interpretation, the budget has the function, rather than being a tool for evaluating the hypothetically feasible alternatives in the company, of a means by which the result of a complex decision-making process is made explicit, within which the individual decisions have already been evaluated with the aid of other, much more refined instruments for measuring the income/financial impact of the choices. From this point of view, we can understand this document to assess the economic viability of the various management alternatives that the hotel business could implement.

\section{Motivation function}

For the objectives indicated in the budget achieved, it is necessary that these parameters have been "internalised" by company managers. In this context, the drawing up of the budget can play an essential role as a motivational tool so that the set objectives are "owned" by the subjects involved in this process. The performance of this function is heavily influenced by the management style adopted by the company. As long as the heads of the various company departments (Food \& Beverage, Room Division, and others):

- will be imposed the objectives to be achieved without any real participation in their choice,

- will be forced to pursue objectives deemed impossible to achieve,

- will have the perception that the ex-post measurements are incorrect,

- will be substantially denied the decision-making levers through which they could intervene in order to achieve the objectives set,

- will be the subject of a pseudo-participation that formally sees them as the leading players in determining the objectives but which, on a substantial level, makes them mere executors of decisions taken by other subjects, the budget will certainly not be able to develop any "motivational" role within the company. For this to happen, the budgeting process must take place in a company climate that is favourable to the active participation of managers. Real participation in the drawing up of the grid of objectives to be achieved and the execution - substantial and not only formal - of the delegation process, therefore, are two unavoidable conditions for the budget itself to play the role of motivational tool.

In conclusion of what has been said so far, we can remember how some scholars talk about imposed budgets and participatory budgets. The writer believes that an "imposed budget" is no longer, in reality, a real budget because, in such a context, such a document sees its proper function wholly distorted. A so-called imposed budget is apparently a budget because its form is analogous to that of a real participatory budget, but in reality, it represents only a set of values without substantial relevance and management significance. The participation of managers in the determination of the values expressed in the budget is, therefore, the discriminating element so that the document analyzed is really a budget and not just a jumble of accounting values which, lacking the most relevant element, are unlikely to influence the management action of managers somehow.

\section{Communication function}

Often within the company, one of the unresolved problems that inevitably creates "discomfort" among managers is the lack of communication of the objectives to which managers operate. There is no need to go into further detail to understand how complete or partial ignorance of the goals to which management action should be directed leads at least to a reduction in business effectiveness. The communication to managers of the objectives to be pursued is, therefore, a necessary step so that the company's performance does not suffer. The budget is undoubtedly the most suitable communication tool for the dissemination of such information because:

- it is expressed in quantitative-monetary terms,

- presents a concise part accompanied, however, by a series of analytical documents explaining, in every possible dimension, all the intermediate objectives on the attainment of which the achievement of the overall business objectives depends,

- Moreover, is, or should be, marked by a clear and intelligible form by the addressees.

These characteristics make it possible to consider the budget an excellent means of global business communication, which, inevitably, must be supplemented by a series of additional information documents without which the information support to managers' activities would inevitably be limited and incomplete.

In conclusion, therefore, we can say that the company can only achieve the objectives that have been set if:

- The action of all subjects is aimed at achieving those objectives;

- Everyone knows the objectives to be pursued.

The explanation of these elements, given their "obviousness", may seem trivial. On the other hand, company reality frequently shows situations in which knowledge of the general business objectives is the exclusive patrimony of top management. This makes the behaviour of managers who are not part of this privileged "caste" erratic. If the goal is unknown, the management activity will be at least random or better, and it will be based on a subjective interpretation by the individual managers of what, at least in theory, should be the business objectives. Such an interpretative effort will inevitably lead to individual results as they will be derived from personal analysis of the managers involved. Such management is likely to be studded with small and large problems that prior planning could, if not eliminate, at least reduce.

Assigning a communication function to the budget, therefore, means emphasising how this document must be considered indispensable if the management of the hotel business is to be aimed at maximising effectiveness and efficiency.

\section{Instrument function usable at the end of the evaluation of managerial performance oversize control function}

Since the evaluation of managerial performance cannot be separated from the comparison between objectives and actual values; the budget represents a tool through which it is possible to implement a phase of evaluation of the work carried out by managers. In order for this function to be carried out positively, however, it is necessary that: 
- The objectives expressed in the budget are realistic and have been set with the intention of motivating the subjects. This condition implies the rejection of both overly ambitious objectives and objectives that can be achieved without a particular commitment. In both cases, the exact value could certainly not play a role as a motivating factor at the motivational level because in the first case it would be perceived as impossible to achieve and in the second case as an achievable value in any case.

- The final values are determined correctly and are perceived as objective values free from any manipulation.

If the measurement of performance is carried out in this context, the budget may be a useful element for valuation purposes. If, on the other hand, one of the conditions indicated above is no longer met, the budget could no longer be considered a tool to assist in the evaluation of managerial performance.

\section{Participation function to decisions}

This function is strictly related to the "motivational" function assigned to the budget and illustrated in the previous pages. This function can only be effectively performed if there is, within the hotel business, a management style favourable to participation. As has already been seen when illustrating the motivation and performance evaluation functions assigned to the budget, it is not so much the budget itself that enables this function to be carried out, but the management style in which the company is managed. If, however, the management style is actually and not only externally participatory, the budget helps to ensure that the participation of the various managers involved is formalised and allows explicit objectives to be achieved through concerted action by several corporate bodies.

In the absence of such characteristics, it is undoubtedly not the drafting of a formal document such as the budget that can ensure that specific individuals participate in the management of the company.

In conclusion, we believe we must stress that the participation of managers in the decision-making process should not be understood as a means of eliminating any responsibility and interest in the management of the company on the part of top management.

Therefore, talking about the participation function that the budget can perform makes sense only in a company structure where top management shows a deep interest in the budget and planning. If operational managers perceive the absence of such interest, the company's programming will likely be transformed from a valid management tool into a mere formal procedure and, consequently, the budget will become a document in the drafting of which many people participate, but nobody believes in its usefulness..

Function of anticipation of the problems that, hypotetically, may result in the company

The drafting of a composite document such as the budget means that the company management is substantially obliged to consider in particular depth the different scenarios that the hotel may be facing in the period considered. This analysis presupposes the early identification of the various problems that the company might, at least in theory, have to solve in the future. The identification of such "events" often occurs even in the absence of formal planning. The entrepreneur, in fact, generally tends to "anticipate" what the external economic environment could reserve for him in the following months. Even in this case, however, the implementation of a formalized and composite programming such as that which leads to the drafting of the operating budget should - the conditional is, however, a must - allow a more in-depth analysis of "future problems" than that carried out in a management context in which improvisation is the dominant feature.

Also, in this case, therefore, the identification of future problems is not so much made by the budget itself, but by the management logic that the drafting of the budget should assume.

A superficial analysis of the characteristics of the hotel business could lead us to believe that the role played by the budget within this business reality is relatively limited. In hotels, it is well known that more than $60 \%$ of the budget is, in fact, "predefined" in the start-up phase of the business. This is due to the fact that many business costs depend on the following three elements, which are identified when the hotel is set up:

1) Localization;

2) Size;

3) Structure in logistical terms.

\section{Location}

About the location, it should be noted that the decision to do so has a substantial impact on both costs and revenues obtainable from operations. Indeed, location defines insufficiently precise terms, the possibility of selling the product placed on the market by the hotel company. The establishment of a hotel in a spa area rather than, for example, in a business town, has a significant influence on the seasonality of sales and also on the possibility of providing ancillary services to the essential hospitality product. Think, for example, of the fact that the location of a hotel near an exit from the motorway tends to place the company in the range of hotels connected to business tourism. Only in such facilities is it logical to provide ancillary services such as secretarial services, interpreters, etc., as the use of such products is related to business tourism and certainly not to leisure tourism. As well as services such as beauty booth, beauty services, solarium, etc., it is appropriate to place them in hotels mainly related to leisure tourism as business travellers generally do not use such products.

The location also has a massive influence on the transport costs borne by the company. If the hotel is set up in an area where there is a lack of infrastructure and public services air, rail, underground - that can be used, it will be essential to establish a permanent transport structure to facilitate the movement of customers (e.g. shuttle buses). It is obvious how the provision of such services causes high costs, the size of which, is intimately interconnected with the location, is essentially predefined in the phase of company formation.

\section{Dimension}

The choice of size also has cost/revenue consequences as long as the company operates. As far as structural costs such as the depreciation of the building, furniture, etc. are concerned, it is evident that these harmful income 
components are substantially defined when the company is set up. Although these costs may, of course, be subject to changes over time, they depend directly on the size that the person setting up the business initially deems appropriate.

In this respect, it should be pointed out that, particularly about hotel businesses, the decision regarding the size of the business should never be dictated solely by the amount of initial capital available. If the discriminating factor were only the financial aspect of the operation, the risk of setting up a hotel which is over or undersized about the potential of the place of the establishment would be extremely high. Since the hotel company must have as its objective the saturation of the rooms, as a result of the lack of possibility of storage of the product placed on the market, the choice of size must be made on the basis of considerations that are not merely financial, but strategic, supported by in-depth market analyses with a time horizon of at least 5 or 10 years.

While it is evident that the size of the company affects structural costs, it must also be stressed that this decision has a substantial impact not only on depreciation and amortisation but also on several other income elements that are only indirectly linked to the choice of size. We intend to refer here to the total service costs that are directly proportional to the size of the hotel. The larger a hotel is, the higher will be the need for staff such as concierge, reception, cleaning, porterage, auxiliary services, etc.. The amount of these costs is therefore directly related to the size, and it is for this reason that this choice develops a strategic value unknown in other companies.

\section{Structure in logistical terms}

The logistical structure of the hotel also represents a decision which, although it was taken at the time the company was set up, reflects its reflections as long as the company operates in the market. Structuring the hotel well in logistical terms means laying the foundations for considerable savings in terms of service costs. Just think, for example, how the structure of the services heavily influences the time needed for their cleaning, how the structuring of the floors has a significant impact on the amount of service personnel on each floor, how the location of the kitchen has a significant impact on the quality and quantity of work carried out by the staff in the room, etc.. The logistics of a hotel therefore constitutes a decision making element of primary importance in the strategic choices to be made during the company's establishment phase. On this choice depend a grid of other decisions, which, in turn, will lead to higher or lower costs. The strategic dimension of this choice appears in its entirety when considering the number of personnel costs that are directly or indirectly connected with the decision in question.

The observation that a substantial part of the business costs of a hotel company is, at a substantial level, predefined during the start-up phase of the company, with the consequence that almost $60 \%$ of the values entered in the budget depend, directly or indirectly, on choices made when the company was established, could lead to the erroneous conclusion that, in this economic-entrepreneurial reality, the budget plays a relatively unimportant role. According to this profoundly distorted viewpoint, the observation of the strategic importance of the decisions regarding location, size and logistical structure and the consequences at the level of service/revenue costs that such choices implicitly imply, should lead to the conclusion that the planning that, year after year, managers must carry out is of limited importance. Such a conclusion is unsustainable from both a theoretical and operational point of view. At a theoretical level the idea that, in the presence of specific cost structures, characterised by the substantial immobility of numerous harmful income components and the impossibility of storing products placed on the market, programming should be relegated to playing a secondary role must be rejected. In such situations, on the other hand, scheduling becomes a management element that cannot be eliminated because the coverage of fixed costs represents an objective, the failure to achieve which can seriously undermine the economic stability of the company even if the imbalance lasts for a relatively short period.

Also, from an operational point of view, the underestimation of the importance of the planning and therefore of the budget in the hotel business cannot achieve consensus. In fact, it is often the managers themselves who, fully understanding the seriousness of the consequences deriving from "random" management of the hotel entrusted to pure epidermal sensations, require serious business planning.

Therefore, although a large part of the hotel company's budget is substantially predefined when the company is set up, it can be said that the planning and the budget take on a significant importance within this business reality, due, on the one hand, to the need to saturate the production capacity and, on the other hand, to the impossibility of storing the products placed on the market.

The budget can only adequately fulfil the functions outlined above if it is drafted with a proactive attitude towards the external environment in mind. Hotel managers need to anticipate problems and put themselves in an active position - and therefore potentially liable to induce behaviour in third parties - concerning their surroundings. Prediction, i.e. the simple identification of the various scenarios that could occur as a result of a passive attitude on the part of the company, is therefore, only one stage in the planning process. Forecasting can in fact be useful to understand the lines of action to be implemented so that the company's objectives can be effectively achieved. However, this phase must necessarily be followed by a moment of rethinking the consequences deriving from the application of active company policy, capable of modifying, to a more or less sensitive extent, the external environment and the behaviour of potential customers. Seen in this perspective, the budget can certainly not be the result of the mere extrapolation of actual data. In fact, a proactive attitude requires a rethinking of the objectives that may have been set in previous years in the light of the changes in behaviour that the company intends to implement. The mere extrapolation of past data also has a limit that may prevent the implementation of effective and efficient management of the company. We are referring here to the fact that the setting of objectives based on actual values tends to perpetuate the operationalmanagement conditions that those data summarise. This self-perpetuating situation can hide pockets of inefficiency and ineffectiveness. It is enough to think for example of the case in which for several years the management of a hotel has omitted any form of marketing with the result of a constant under-occupation of the rooms. A circumstance that, in addition to the negative effects within the Room Division, also causes deleterious consequences in the Food $\&$ Beverage section because, the lack of customers is also reflected in the occupation of the restaurant, the use of the 
bar inside the hotel, and so on. It is clear that as long as the objectives are set according to extrapolation logic, the under-occupation of the rooms can certainly not be overcome, just as any identifiable inefficiencies in the kitchen (due to waste, theft, elimination of damaged food due to poor conservation, etc.) or in other areas of the company (due to waste in cleaning materials and/or time spent cleaning each room, etc.) are also reproduced over time.

As long as the objectives are set within a logic of pure extrapolation of the final data, these company "gaps" are destined to reproduce over time since, within such a vision, the improvement of the company's performance is certainly not part of the primary aims of the planning.

The overcoming of the extrapolation logic does not, of course, imply the rejection of the idea that the final values represent a good starting point so that the determination of the objectives to be achieved is not only a perfect theoretical operation without any link with the company reality. Considering, for example, how many rooms were placed on the market the previous year, or how much food consumption in the kitchen in the past, it is not only appropriate but also represents an essential cognitive element for a correct drafting of the budget. This does not imply, however, that this is the last stage that leads directly to the drafting of this document. In fact, after the analysis of the final balance, it is necessary to move on to the next phase of identification of the real objectives to be achieved, a phase which, as can be easily understood, is the discriminating element so that the planning represents a valid tool to improve, in substantial terms, the effectiveness and efficiency of hotel management as a whole.

At the end of these brief observations, it should be stressed that the budget. However, it represents one of the main tools that can potentially help to rationalize the decision-making process of the hotel company, is characterized by some limitations that make it advisable to integrate it with other means that allow the disclosure of elements that cannot be deduced from the document we are interested.

The most evident limit that, in reality, represents at the same time the characteristic that makes the budget an instrument of primary importance in the management field, is the fact that the objectives are made explicit in strictly quantitativemonetary terms. If, on the one hand, this makes the budget the ideal communication tool and the means to unambiguously express, without the possibility of misinterpretation, the set objectives, on the other hand it means that this document cannot measure objectives that can be expressed in terms of effectiveness such as the quality of the product placed on the market, the level of service available to the customer, the market share that is intended to be achieved, etc.

This, therefore, requires that the information elements of a quantitative-monetary nature that can be deduced from the budget are combined with a set of news and parameters of an exquisitely qualitative nature. Only in this case, can the budget play its proper role. If, on the other hand, an exhaustive information capacity is attributed to the budget with respect to any managerial necessity, there is a risk due to an overestimation of the potential information capacity of the instrument in question - that the effects that can derive from the use of this document will be reduced.

These brief observations on the planning highlight how the budget cannot, in itself, improve the management of the hotel business if the drafting of this document is not accompanied by a cultural-philosophical approach aimed at business effectiveness and efficiency which, in order to be useful, must permeate all hierarchical levels of the business. The formal document is therefore useful, or rather, indispensable, only when it represents the output of a part of a process whose complexity can indeed not be summarized in a series of quantitative-monetary values.

The drafting of the budget must, therefore, be considered the starting point and not the arrival point of a long and complicated managerial activity. The budget does not solve problems, but merely makes them explicit and provides the keys to interpret the potential solutions that can be adopted. The budget, therefore, cannot be interpreted as a substitute for the management action that managers must carry out daily because such an interpretation would, without a shadow of a doubt, be destined to provoke extremely negative consequences at both income and financial level.

If it is true that the budget cannot be interpreted as a substitute for the management action of company managers, it is equally valid that even the programming must be free from misleading interpretations about its possible substitutability with the management of the company.

\section{Master budget and operating budget in hotel}

After making a few theoretical observations on the programming and budget, it is necessary to illustrate how this document should be structured at a formal level.

The documents that make up the budget (which will be discussed in more detail in the following paragraphs) can be divided into two main categories:

- operating budgets;

- corporate master budget.

The perspective, according to which operating budgets are drawn up could be defined as "sectoral in nature". In these documents, in fact, the company is divided into management areas in relation to which the objectives to be pursued are quantitatively explained. Within the hotel business, operating budgets can be identified as follows:

- Budget Room Division

- Food \& Beverage budget;

- Golf budget;

- budget for other sports and aesthetic activities;

- Health club budget;

- other operational departments' budgets;

- rent, concessions, commissions and other revenue budgets;

- marketing budget;

- administrative and general costs budgets;

- investment budgets.

The drafting of these "partial" documents as a whole leads to the identification of a series of objectives which, for the reasons explained above, although formally set out in a variety of different schedules, must be characterized by an overall intrinsic coherence.

Programming is therefore carried out by applying the instruments allowing the medium and long-term maximization of operating income. The programmed values indicated in the various operating budgets, therefore, derive from the choice of the alternative which, based on the various control instruments that can potentially be used, is the most convenient. 
The summary of the values indicated in the various operating budgets leads to the preparation of the corporate master budget, which is initially made up of a balance sheet and a profit and loss account which, apparently, can be mistaken for the documents making up the financial statements but which, in reality, compared to those, are characterized by a substantial difference: while the accounting values of the financial statements are in fact final, the data included in the budget are strictly preventive, or rather, planned.

For reasons of data analysis, the balance sheet and profit and loss budget should be reclassified according to the schemes used to analyze the financial statements. In this way, it is possible to directly compare the various aggregates resulting from the reclassification of both planned and actual data.

However, the preparation of the master budget is concluded only after having verified the financial feasibility of the planned values. After ensuring coordination between the various intermediate objectives, the person drawing up the budget must, in fact, check that the financial aspect of what has been established in the operational budgets does not represent an obstacle to the effective implementation of the programme. Checking the financial feasibility of the programmes set out in the partial budgets - the implementation of which presupposes the drawing up of the financial budget - is, therefore, a step that completes the budgeting process. Should the analysis highlight the impossibility, from a financial point of view, to carry out the planned programmes, it is necessary to call into question any objective previously identified.

A programmed value without financial coverage is only improperly defined as an "objective" because, in reality, this value represents only a mere dream destined, due to lack of funds, to remain so.

If, on the other hand, the financial feasibility of operating budgets is ascertained, it is possible to proceed with the preparation of the financial budget, which represents a financial statement drawn up based on the planned values. Also in this case, the difference between the overall financial budget and the financial statement is that the first document identifies planned values while the second is drawn up on the basis of actual data. However, the form can be entirely identical. About the verification of the financial feasibility of the programmes, it must be pointed out that this determination must be made in light of the most advanced financial instruments. Often, however, in small and medium-sized enterprises, the same budgeting process is carried out in an imperfect and deficient way and, consequently, it is unthinkable to hypothesize the application, in such situations, of evolved financial instruments. For this reason, chapter VII is dedicated to financial programming in small and medium enterprises, where, frequently, it is necessary to sacrifice some theoretical elements of control and budgeting in order to provide the enterprise with a series of programmed values if, although not perfect, they can represent the first step towards a more appropriate use of the economic, financial and patrimonial programming tools of the enterprise.

The preparation of the three documents that make up the master budget (balance sheet budget, profit and loss budget and financial budget) concludes the budgeting process.

It should be noted that the more exhaustive the operational budgets are of the various management areas, the more it is possible to state that the sum of the values of these budgets identifies the data indicated in the master budget.

It is evident how, for example, if the company does not proceed with an operating budget of financial charges, the data of interest expense should be included in the master budget based on economic calculations that have not been substantiated in an area operating document. Thus it may happen, for example, that capital gains, contingent assets, capital losses and so on are expected. These values are not included in any operating budget even though they are present in the master budget of the company.

The pure summation of the operational budget values does not always provide the necessary global vision to draw up the global corporate budget. It is entirely conceivable that some values present in this overall document are not included in any operating budget.

At the end of these brief observations regarding the composition of the budget within the hotel business, it should be noted that the identification of the programmed values included in the documents that we are looking at, presupposes the ex-ante identification of the company mission. The services that hotels place on the market can, in fact, be characterized by deeply differentiated characteristics depending on the type of activity that the hotel intends to implement. Just think of the different types of hospitality that can distinguish hotel companies. In the panorama of companies that offer hospitality are identifiable companies that develop:

- business tourism

- leisure tourism

- tourism-related to conferences and congresses

- spa tourism

- tourism-related to medical and aesthetic activities

- sightseeing

- art tourism, etc.

The identification of objectives and the expression of programmatic values in company budgets must be preceded by a phase in which short-term policies are established, which implicitly identify the businesses within which the company wants to develop its activity.

The values indicated in the various partial budgets, therefore, represent the result not only of the mix of products offered on the market (R.D. service, restaurant service, beauty services, etc.), but also of the business mix that the company has decided to develop.

About the content and form that hotel budgets can take, it is appropriate to make a few observations regarding what is unanimously called the "Uniform System of Accounts for Hotels" (U.S.A.H.). This system dates back to 1926 when the Hotel Association of New York appointed a committee to identify uniform financial statements and department statement of income schemes for the hotel industry. This need for uniformity also led to the drafting of the Uniform System Accounts for Restaurants and the Uniform System of Accounts for Motels and Small Hotels.

The Uniform System of Accounts for Hotels proposes uniform Financial Statements and Departmental Statements, within which each item is commented in order to eliminate, or at least limit, misinterpretations regarding individual accounting items.

The usefulness of these schemes is undoubtedly high as it has allowed and still allows for a "homogenization" in terms of terminology and form of the financial statements that can be used in the hotel sector. Frequently, however, there is a 
"mystification" of this system. Many hotels confuse the U.S.A.H. with the management logic that this system presupposes. It is not by applying such schemes sequentially that the efficiency and effectiveness of the managers' action increases. In order to obtain this result it is necessary that the application of these schedules represents an element that can be placed within the management control process as defined in the previous pages.

It is, therefore, the management control that allows the achievement of objectives that can be expressed in terms of effectiveness and efficiency that are often wrongly attributed to a system - the U.S.A.H. - that, basically, "only" allows to achieve uniformity of language and schemes.

We consider it opportune to underline how, frequently, the prospectuses indicated by the U.S.A.H. are applied in the context of every hotel reality, even if foreign to the North American world where this system has seen the light.

Such behaviour cannot be accepted because if on the one hand it is true that such schemes represent a relevant reference point as they are the result of an in-depth study by authors and experts in the sector, on the other hand, it is equally true that their application cannot take place uncritically and automatically in economic-financial-social realities different from the country where the prospectuses have been drawn up.

From these considerations, it can, therefore, be deduced that the U.S.A.H., while positively representing a useful operational element for those who carry out their activities in the hotel sector, is a "perfectible" tool that should not be interpreted as the panacea for all the management/accounting problems of a hotel company.

The U.S.A.H. is, therefore, a set of schemes whose use must be preceded by a careful analysis of the appropriateness of adapting, and therefore also significantly modifying, these prospectuses in such a way that the schemes applied in a specific company reality can capture and highlight the elements that, in the company under consideration, assume particular importance.

\section{Conclusions}

The budget in a hotel, until a few decades ago, could be considered an optional extra with respect to financial reporting and its analysis. The annual or multi-annual planning, nowadays, is, instead, an indispensable element for the management of the hotel structure to be carried out effectively and efficiently, maximizing profitability and keeping financial variables under control. The structure of the budget, in order to be usable by managers, must be complex and made up of several documents that go into the company's departments in detail. The absence of a multidocument structure makes the company budget totally devoid of any management utility.

\section{References}

1. Allen MD. Accommodation and cleaning services, Vol. II, Hutchinson, London 1983.

2. Allen MD, Myddeltong DR. Essential management accounting, Prentice Hall, New York 1987.

3. Avi MS, Management Accounting, cost analysis, Eif e--book 2012, 2.

4. Asiedu Y, Gu P. Product life cycle cost analysis: state of the art review, International Journal of Production Research 1998, 36(4).
5. Avery P. Calculating life cycle cost. Detailed calculation can unearth hidden savings, Engineered System, September 2011.

6. Bayou ME, Bennet LB. Profitability Analysis for Table-Service Restaurants, The Cornell H.R.A. Quartely, April, pages 1992;24-48.

7. Bedford NM. Extension in accounting disclosure, Prentice-Hall, Englewoods Cliffs, New Jersey 1975.

8. Belkoui A. The impact of socio-economic accounting statements on the investment decision: an empirical study, in Accounting, Organization and Society 1980;3:263-283.

9. Bennet LB, Bayou ME. Profitability Analysis for Table-Service Restaurant, the Cornell H.R.A. Quartely 1992.

10. Billington J. The ABCs of ABC: activity-based costing and management, Harvard Management Update 1999, 4(5).

11. Brimson JA. Activity Accounting: An Activity - Based Costing Approach, John Wiley \& Sons, Inc., New York 1991.

12. Burrows G, Chenhall RH. Target costing: first and second comings, accounting history review 2012, 22(2).

13. Coobs H, Hobbs D, Jenkins E. Management accounting: principles and applications, Sage pubblications, London 2005.

14. Cooper R, Chew WB. Control tomorrow's costs through today's designs - Target costing lets customers, not the product, set the price, Harvard Business Review 1996, 74(1).

15. Cooper R. Cost management concepts and principles The rise of activity-based costing - Part four: what do activity-based cost systems look like? Journal of cost management for the manufacturing industry, spring 1989.

16. Cooper R. Cost management concepts and principles The rise of activity-based costing - Part one: what is an activity-based cost system? Journal of cost management for the manufacturing industry, summer 1988.

17. Cooper R. Cost management concepts and principles The rise of activity-based costing - Part three: how many cost drivers do you need, and how to select them? Journal of cost management for the manufacturing industry, winter 1989.

18. Cooper R. Cost management concepts and principles The rise of activity-based costing - Part two: when do I need an activity-based cost system? Journal of cost management for the manufacturing industry, Fall, 1988.

19. Cooper R., Kaplan R. S., Activity-based system: measuring the cost of resource usage, accounting horizons, September 1992.

20. Cooper R, Kaplan RS. Measure Costs Right: Make the Right Decisions, Harvard Business Review 1988.

21. Cooper R. The Rise of Activity Based Costing - Part Four: What do Activity Based Cost System look like? Journal of cost management foe the manufacturing industry, Spring 1989.

22. Cooper R. The Rise of Activity Based Costing - Part Three: How many Cost Drivers do youneed, and how do you select them? Journal of cost management foe the manufacturing industry, Winter 1989.

23. Copper R, Kaplan RS. Profit priorities from activitybased costing, Har vard Business Review 1991. 
24. Cooper R, Kaplan RS. Activity-based system: measuring the cost of resource usage, accounting horizons 1992.

25. Cooper R, Slagmulder R. Develop Profitable New Products with Target Costing, Sloan Management Review, summer 1999.

26. Cooper R, Slagmulder R. Target Costing and Value Engineering, Productivity Press, Portland, Oregon 1997.

27. Cooper R, Slagmulder R. Target costing and value engineering, Productivity press: the IMA foundation for applied research, Portland-Montvale 1997.

28. Denney G, Rutherford O'Fallon MG. Hotel Management and operation, Wiley 2007.

29. Fay CT, Jr Rhodads RC, Rosenblatt RL. Managerial accounting for the hospitality service industries, WM. C. Brown Company, Dubuque Iowa 1980.

30. Forgacs G. Brand asset equilibrium in hotel management International Journal of Contemporary Hospitality Management 2003;15(6):340 342.

31. Geller AN. Rule Out Fraud and Theft: Controlling Your Food-Service Operation, The Cornell H.R.A. Quartely, December 1991, 55-65

32. Glugh P, Baumann H. The life cycle costing (LCC) approach: a conceptual discussion of its usefulness for environmental decision-making, In Building and Environment 2204;39:123-136.

33. Gonzalez R, Gasco J, Llopis J. ICTs in hotel management: a research review, International Journal of Contemporary Hospitality Management 2019;31(9):3583-3609.

34. Heijunges R, Huppes G, Guinee JB. Life cycle assessment and sustainability analysis of products, materials and technologies. Toward a scientific framework for sustainability life cycle analysis, Polymer Degradation and Stability 2010;95(3):134-145.

35. Heitger L, Ogan P, Maturlich S. Cost Accounting, South-Western Publishing Co 1992.

36. Atadil A, Green A. An analysis of attitudes towards management during culture shifts, International Journal of Hospitality Manament 2020, 86.

37. Hoque Z. Handbook of cost and management accounting, Spiramus Press 2005.

38. Horngren CT. A Contribution Margin Approach to the Analysis of Capacity Utilization, The accounting Review 1967;42(2):254-264.

39. Horngren CT, Datar SM, Rajan MV. Cost accounting: a managerial emphasis, Pearson Prentice Hall 2012.

40. Hughes HL. Economics for hotel and catering students, Hutchinson London 1986.

41. Ivanova M, Ivanov S, Magnini VP. The Routledge Handbook of Hotel Chain Management, Routledge 2016.

42. Jensen MC, Mecking WC. Theory of the Firm: Managerial Behavior Agency Costs and Ownership Structure, in Journal of Financial Economics, NorthHolland Publishing Company 1976, 4.

43. Juras P, Peacock E. Applying Strategic Cost Analysis Concepts to Capacity Decisions, Management Accounting, Quarterly, Fall 2006;8(1):1-15.

44. Jones P, Lockwood A. The management of hotel operations, Cassel 1989.

45. Kotas R. Management accounting for hotels and restaurants, Blackie Son Ltd, Glasgow 1986.
46. Langfield-Smith K, Thorne H, Hilton WR. Management accounting : information for managing and creating value, McGraw-Hill 2006.

47. Lewis RJ. Activity-based models for cost management systems, Quorum Books 1995.

48. Kankey R, Robbins J. Cost analysis and estimating: Shifting U.S. priorities, Springer-Verlag 1991.

49. Kaplan RS, Anderson SR. Time - Driven Activity Based Costing, Social Science Research Network 2003.

50. Kaplan RS, Cooper R. Cost \& Effect: using integrated cost systems to drive profitability and performance, Harvard Business School Press, Boston, Massachusetts 1998.

51. Kaplan RS, Shank JK, Horngren CT. Contribution margin analysis: no longer relevant/strategic cost management: the new paradigm, Journal of management Accounting Research,, Fall 1990, 2-15.

52. Kaplan RS, Anderson SR. Time-driven activity-based costing: a simpler and more powerful path to higher profits, Harvard business school Press 2007.

53. Kimes SE, Barrash DI, Alexander JE. Development a Restaurant Revenue management strategy, Cornell Hospital Quartely 1999;(5):18-29.

54. Lado-Sestayo R, Vivel-Búa M, Otero-González L. Determinants of TRevPAR: hotel, management and tourist destination, International Journal of Contemporary Hospitality Management 2017;29(12):3138-3156.

55. Langfiel Smith K, Thorne H, Hilton RW. Management accounting, in formation for managing and creating value, McGraw - Hill Irwin 2006.

56. Lebruto S, Farsab B. A Measured Approach to FoodInventor Management, The Cornell H.R.A. Quartely 1993.

57. Lesser DH, Rubin K. Rates of Return on Hotel Investments, in The Cornell H.R.A. Quartely 1992, 234-259.

58. Lewis RJ. Activity-Based Models for Cost Management Systems, Quorum Books 1995.

59. Lucey T. Management Accounting, Letts educational 1996.

60. O'guin MC. The complete guide to activity - based costing, Prentice Hall, Eglewood Cliffs, New Jersey 1991.

61. Okano K. Life cycle costing - An approach to life cycle cost management: A consideration from historical development, Asia Pacific Management Review 2001, $6(3)$.

62. Monden U, Hamada AK. target costing and kaizen costing in Japanese automomile companies, Journal of Management Accounting Research Fallen 1991;3:234246

63. Moro PC, Da Luz LM, Zocche L, De Francisco A. Assenssment an entrepreneurial tool for business management and green , Journal of Technology Management and Innovation 2013;8(1):1-13.

64. Pavesic D. Cost/margin analysis: a third approac to menu pricing and design, International Journal of Hospitality Management 1983;2(3):127-134.

65. Pesic TV, Andriajasevic M. Cost management in the internal value chain of integrated application of activity - based costing, kaizen concept and target costing, Megatrend Review 2014, 11 fasc. 4. 
66. Rebitzer $\mathrm{G}$ et al. Life cycle assessment Part 1: Framework, goal and scope definition, inventory analysis, and applications, Environment International 2004, 30, fasc. 5.

67. Simons, Robert. Performance Measurement and Control Systems for Implementing Strategy, New international edition, Pearson 2014.

68. Stratton WO. Desroches D. Lawson RA, Hatch T. Activity - Based Costing: Is It Still Relevant? Management Accounting Quarterly Spring 2009, 10(3).

69. Vercio A. Contribution Margin and Fixed Cost per Unit: When to Use and When Not to Use These Analytical Tools, Wiley Periodicals 2017.

70. Warren CS, Reeve JM, Duchach JE. Accounting, South - Western Cengage Learning, Mason, Ohio 2011.

71. Wilhelm WB. Incorporating product life cycle impact assessment into business coursework, Business Education Innovation Journal 2013;5(1):13-23.

72. Wilkinson A, Redman T, Snape E, Marchington M. Managing with Total Quality Management. Theory and Practice, Macmillan, London 1998.

73. Woodward DG. Life cycle costing - Theory, information, acquisition and application, International Journal of Project Management 1997;15(6):35-47.

74. Zhang Z, Li H, Meng F, Li Y. The effect of management response similarity on online hotel booking: Field evidence from Expedia, International Journal of Contemporary Hospitality Management 2019;31(7):2739-2758. 